\title{
Study on the influence of fly ash and silica fume with different dosage on concrete strength
}

\author{
GUO Yin-le ${ }^{1}$, LIU Xue-ying ${ }^{1 *}$, and HU Yue-ping ${ }^{2}$ \\ ${ }^{1}$ Zhejiang University of Water Resources and Electric Power, 310018 Hangzhou, Zhejiang, China \\ ${ }^{2}$ Zhejiang Huanlong Environmental Technology Co., Ltd, 324400 Quzhou, Zhejiang, China
}

\begin{abstract}
In order to improve the compressive strength of concrete, mineral admixtures can be added to concrete to replace part of the cement(C). Commonly used mineral admixtures include fly ash(FA) and silica fume(SF). Through a series of experiments, the effect of adding different amounts of fly ash and silica fume and double mixing on the strength of concrete was studied by using the same amount of substitute for cement under the same water-binder ratio. The results show that fly ash has a certain influence on improving the fluidity of concrete, and the influence on the strength of concrete is mainly in the later period; the influence of silica fume on the fluidity and strength of concrete is better than that of fly ash, and the main influence of silica fume is on the increase in strength. The early stage and the later stage are slower; the strength of concrete mixed with fly ash and silica fume at the same time increases first and then decreases with the increase of mineral admixtures.
\end{abstract}

\section{Introduction}

With the development of economy and the progress of engineering technology, roads and bridges and other projects continue to extend to areas with complex geology, which requires concrete to have higher performance of concrete $^{[1]}$. Modern building construction is convenient and fast, with high structural strength, diverse structural systems, and complex and changeable use environments. The buildings show the characteristics of high-rise, largespan, lightweight, underground and harsh use environments. The strength of concrete used in the application is increasing day by day ${ }^{[2]}$. Mineral admixture is an important component of modern concrete, which plays an important role in improving the strength of concrete. Reasonable selection of the type and mixing ratio of mineral admixtures is of great significance to improve the construction quality of concrete ${ }^{[3]}$.

Fly ash and silica fume are wastes of industrial development. They are discharged randomly to pollute the environment and endanger health. However, as admixtures of concrete, they have good benefits for improving the strength of concrete ${ }^{[4]}$. Many scientific researchers have carried out in-depth research on this and found that mixing industrial waste such as fly ash and silica fume in concrete has a certain impact on various performance indicators such as concrete strength. This research will study the influence and regularity of different dosages of fly ash and silica fume on the compressive strength of concrete through experiments, and provide reference conditions for the configuration of highperformance concrete.

\section{Materials}

The cement adopts Haolong brand P.O42.5 grade cement, with a specific surface area of $330 \mathrm{~m}^{2} / \mathrm{kg}$, 3days flexural strength of $4.2 \mathrm{MPa}$, compressive strength of $23.7 \mathrm{MPa}$; 28days flexural strength of $7.4 \mathrm{MPa}$, and compressive strength of $47.5 \mathrm{MPa}$.

Fly ash adopts grade III fly ash, with a fineness of $17 \%$, a moisture content of $0.2 \%$, a loss on ignition of $5 \%$, and a water demand ratio of $105 \%$. All indicators have reached national standards.

The silica fume is produced by a processing plant in Shanxi.

The gravel(G) from a stone factory in Quzhou, Zhejiang Province, where the coarse aggregate is produced, uses a continuous gradation of $4.75-19 \mathrm{~mm}$, of which $9.5-19 \mathrm{~mm}$ large stones account for $70 \%, 4.75$ $9.5 \mathrm{~mm}$ small stones account for $30 \%$, and the crush value is $8.5 \%$.

The fine aggregate is made of river sand(S), which is produced in a sand field in Quzhou, Zhejiang, with a fineness modulus of 3.0. The gradation zone of this sand belongs to the second zone sand with a mud content of $1 \%$.

The admixture adopts polycarboxylic acid highperformance water reducing agent (WR), solid content is $10.4 \%, \mathrm{pH}=6.0$, density is 1.024 , and water reduction rate is $27 \%$.

The water(W) is local tap water. 


\section{Experimental Proportioning Scheme}

In order to study the influence of fly ash and silica fume on the strength of concrete, concrete with a water-binder ratio of 0.3 , a sand ratio of $40 \%$, and a total amount of cementitious materials of $527 \mathrm{Kg}$ is the research object. Choose $10 \%, 20 \%, 30 \%$ of fly ash content, $6 \%, 8 \%, 10 \%$ of silica fume content, and study its influence on concrete strength by changing the content of fly ash and silica fume. The concrete mix ratio is shown in Table 1. The mineral admixture adopts the same method to replace cement. The mineral admixture of group A is fly ash, the mineral admixture of group B is silica fume, and the mineral admixture of group $\mathrm{C}$ is powder both coal ash and silica fume are mixed.

Table1. Concrete mix ratio.

\begin{tabular}{|c|c|c|c|c|c|c|c|}
\hline Num & $C / \mathrm{Kg}$ & $\begin{array}{c}F A \\
/ \%\end{array}$ & $\begin{array}{c}S F \\
/ \%\end{array}$ & $S / \mathrm{Kg}$ & $G / \mathrm{Kg}$ & $W / \mathrm{Kg}$ & $\begin{array}{c}W R / \\
\%\end{array}$ \\
\hline $\mathrm{A} 0$ & 527.00 & 0 & 0 & 686 & 1029 & 158 & 2 \\
\hline $\mathrm{A} 1$ & 474.30 & 10 & 0 & 686 & 1029 & 158 & 2 \\
\hline $\mathrm{A} 2$ & 421.60 & 20 & 0 & 686 & 1029 & 158 & 2 \\
\hline $\mathrm{A} 3$ & 368.90 & 30 & 0 & 686 & 1029 & 158 & 2 \\
\hline $\mathrm{B} 4$ & 495.38 & 0 & 6 & 686 & 1029 & 158 & 2 \\
\hline $\mathrm{B} 5$ & 484.84 & 0 & 8 & 686 & 1029 & 158 & 2 \\
\hline $\mathrm{B} 6$ & 474.30 & 0 & 10 & 686 & 1029 & 158 & 2 \\
\hline $\mathrm{C} 7$ & 442.68 & 10 & 6 & 686 & 1029 & 158 & 2 \\
\hline $\mathrm{C} 8$ & 421.60 & 10 & 10 & 686 & 1029 & 158 & 2 \\
\hline $\mathrm{C} 9$ & 379.44 & 20 & 8 & 686 & 1029 & 158 & 2 \\
\hline $\mathrm{C} 10$ & 337.28 & 30 & 6 & 686 & 1029 & 158 & 2 \\
\hline $\mathrm{C} 11$ & 316.20 & 30 & 10 & 686 & 1029 & 158 & 2 \\
\hline
\end{tabular}

Each group of mix ratios were tested for compressive strength. The molding size of the test piece was $100 \mathrm{~mm} \times 100 \mathrm{~mm} \times 100 \mathrm{~mm}$. After the concrete aggregates were evenly mixed by a concrete mixer, they were manually vibrated on a vibrating table to form them. Demolding after 24hours. Indoor maintenance to the prescribed age. The pouring, curing, and compressive strength tests of the cube specimens are tested in accordance with GB/T50081-2019 "Standard for Test Methods for Physical and Mechanical Properties of Concrete".

Table2. Test workload.

\begin{tabular}{|c|c|c|c|}
\hline Performance & Test age /d & $\begin{array}{c}\text { Number per } \\
\text { age }\end{array}$ & $\begin{array}{c}\text { Specimen } \\
\text { specifications }\end{array}$ \\
\hline $\begin{array}{c}\text { Compressive } \\
\text { strength }\end{array}$ & $3 \mathrm{~d}, 7 \mathrm{~d} 、 28 \mathrm{~d}$ & 3 & $\begin{array}{c}100 \mathrm{~mm} \times 100 \mathrm{~mm} \times \\
100 \mathrm{~mm}\end{array}$ \\
\hline
\end{tabular}

\section{Analysis of results}

\subsection{Influence of different content of fly ash and silica fume on the performance of concrete}

The two performance indicators of slump and expansion of each group of concrete have been tested. The experimental results are as follows.

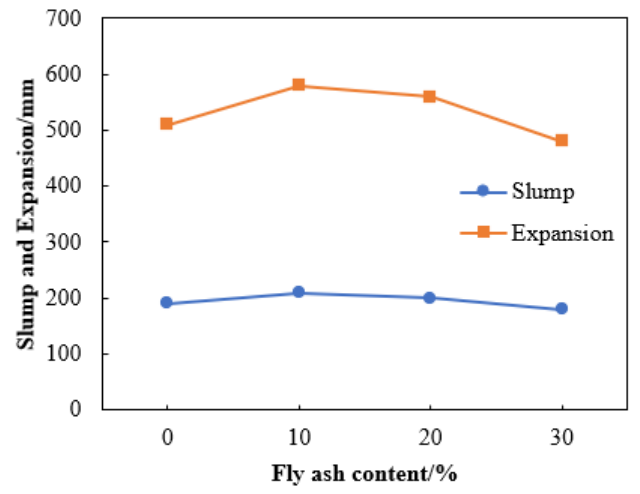

Fig1. Comparison of working performance of concrete with different content of fly ash.

It can be seen from Figure 1 that after replacing part of the cement in the concrete with the same amount of fly ash, the slump and expansion of the concrete mixture have certain changes. With the increase of fly ash content, the slump and expansion degree are also increasing. But when the fly ash content reaches about $15 \%$, with the increase of fly ash, the slump and expansion are continuously reduced, and the concrete is too viscous, resulting in lower fluidity.

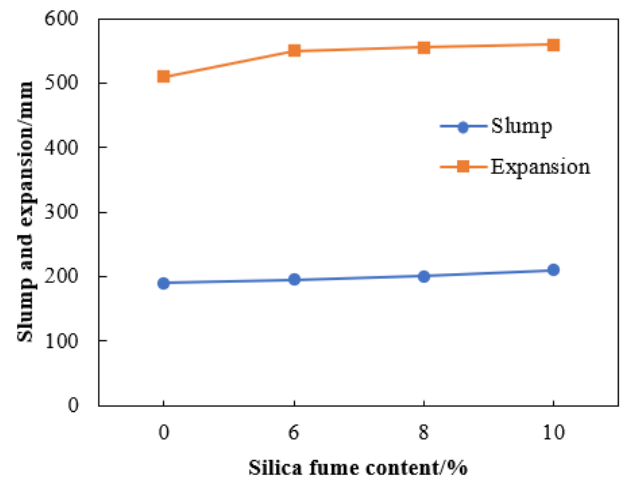

Fig2. Comparison of working performance of concrete with different content of fly ash.

It can be seen from Figure 2 that after replacing part of the cement in the concrete with the same amount of silica fume, the slump and expansion of the concrete mixture are significantly improved. With the continuous increase of silica fume, the degree of slump and expansion are also increasing. This is because silica fume can improve fluidity. On the one hand, the surface of silica fume is covered by a layer of active material, and the silica fume produces a ball between the cement particles, which increases the fluidity of the mixture; on the other hand, silica fume can replace the filling water in the voids of cement particles, turning it into free water, thereby improving the working performance of the mixture. The activity of silica fume is high. When the amount is too high, the viscosity of the slurry will increase and the fluidity will decrease. When the amount of silica fume is further increased, due to the large specific surface area of the silica fume, the excess silica fume will absorb a large amount of water, resulting in an increase in the water demand, and the excess water of the hydration reaction exists in the closed pores of the concrete, which will cause the decrease of its relative density and affect the strength of the concrete ${ }^{[5]}$. 


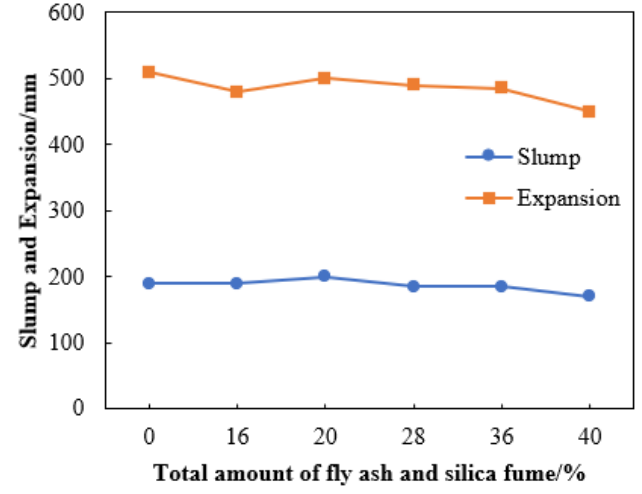

Fig3. Comparison of the performance of concrete with different admixtures.

From Figure 3, it can be found that when fly ash and silica fume are mixed together, the slump and expansion of concrete decrease with the increase of the admixture.

To sum up, the single addition of fly ash can improve the fluidity of concrete, and it will be reduced after excess. The single addition of silica fume can improve the workability of concrete, and the dual addition of fly ash and silica fume can also improve the fluidity of concrete.

\subsection{Influence of different content of fly ash and silica fume on the strength of concrete}

According to the test operation procedure, the test blocks of different ages were measured, and the results are shown in the following table:

Table3. Concrete compressive strength/MPa

\begin{tabular}{|c|c|c|c|}
\hline Serial number & 3d & $\mathbf{7 d}$ & $\mathbf{2 8 d}$ \\
\hline A0 & 51.4 & 55.8 & 62.1 \\
\hline A1 & 50.5 & 62.9 & 77.5 \\
\hline A2 & 48.6 & 57.4 & 70.8 \\
\hline A3 & 31.5 & 41.3 & 55.2 \\
\hline B4 & 58.2 & 77.7 & 88.5 \\
\hline B5 & 61.4 & 80.1 & 89.8 \\
\hline B6 & 63.7 & 82.8 & 90.2 \\
\hline C7 & 40.2 & 57.2 & 63.1 \\
\hline C8 & 44.5 & 59.6 & 75.4 \\
\hline C9 & 43.7 & 58.7 & 72.1 \\
\hline C10 & 39.7 & 48.7 & 61.5 \\
\hline C11 & 31.5 & 42.7 & 58.5 \\
\hline
\end{tabular}

\subsubsection{Influence of Single Mixing Fly Ash on Concrete Strength}

Figure 4 shows the compressive strength of concrete when only fly ash is added. It is observed that as the amount of fly ash increases, the compressive strength of concrete first increases and then decreases. Because fly ash has a significant active effect, the active ingredients can react with cement hydration products to form a pozzolanic reaction to form $\mathrm{CSH}$ gel, which improves the interfacial bonding strength correspondingly. There are less cement hydration products in the early stage, and fly ash participates in the secondary There is less chemical reaction, which leads to the decrease of the compressive strength of the concrete in the early stage. In the later stage, with the continuous increase of cement hydration products, it promotes and accelerates the pozzolanic reaction, which greatly promotes the growth of the later strength of the single-mixed fly ash concrete ${ }^{[6][7][8]}$. However, the amount of fly ash should not be too much. Obviously, the amount of $10 \%$ has a greater impact on the strength of concrete.

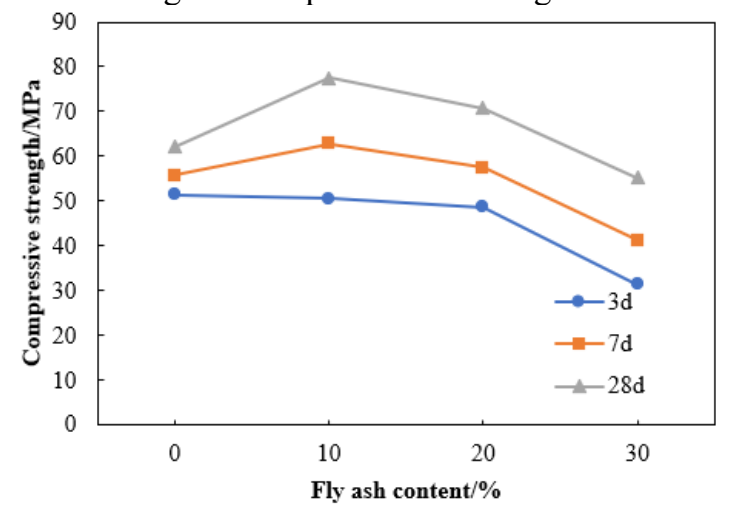

Fig4. Change of concrete strength when only adding fly ash.

\subsubsection{Influence of Single Silica Fume on the Strength of Concrete}

Figure 5 shows the strength of concrete when only silica fume is added. Observed from Figure 5, the strength of concrete is also increasing with the continuous increase of silica fume. After analyzing the strength of $3 \mathrm{~d}, 7 \mathrm{~d}$ and $28 \mathrm{~d}$, it is found that silica fume has a greater influence on the strength of concrete in the early stage, and the later influence is smaller than that of fly ash. Among them, 10\% has the greatest influence on the strength of concrete. Compared with the influence of fly ash alone on the strength of concrete, the influence of silicon fume alone on the strength of concrete is greater in both the early and late stages.

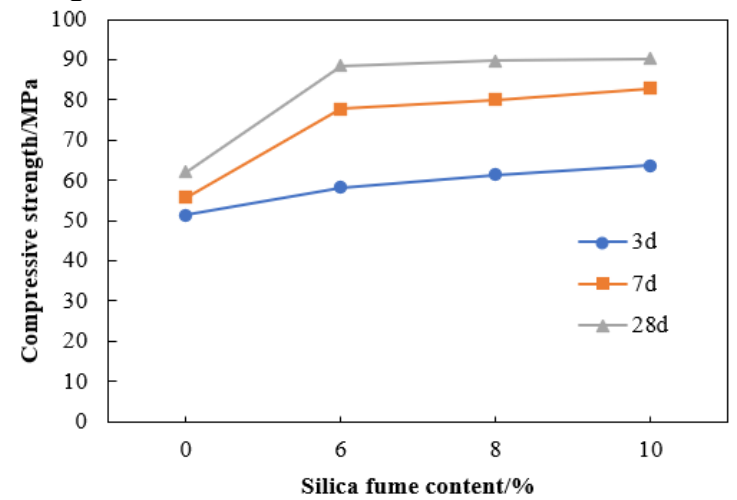

Fig5. Change of concrete strength when only adding silica fume.

\subsubsection{Influence of double mixing fly ash and silica fume on the strength of concrete}

Figure 6 shows the double mixing of $10 \%$ fly ash and $6 \%$ silica fume, $10 \%$ fly ash and $10 \%$ silica fume, $20 \%$ fly ash and $8 \%$ silica fume, $30 \%$ fly ash and 6\% silica Powder, 30\% fly ash and $10 \%$ silica fume concrete compressive strength. Analysis of this shows that with the increase of mineral admixture, the strength of concrete first increases and then decreases. It is lower than the strength of fly ash or silica 
fume alone. Although the strength has increased in the later period, the strength value is still low with the increase of the dosage, indicating that when the dosage is too large, the amount of cement is small, and relatively few highstrength gel products are generated, resulting in lower strength.

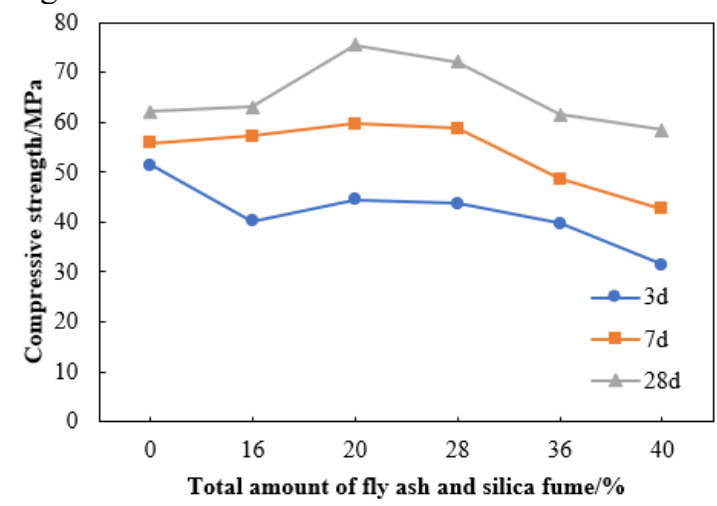

Fig6. Concrete strength change when double mixing.

\section{Conclusion}

In the case of a fixed water-binder ratio and total amount of cementitious materials, adding a certain amount of fly ash and silica fume can increase the strength of concrete and other physical and mechanical properties by replacing cement in the same amount.

When the same amount of fly ash is added separately to replace cement, the strength change trend is to increase first and then decrease. The strength in the early stage increases slowly, and the increase in the later strength increases. When the fly ash content is $10 \%$, the concrete strength reaches the maximum and the fluidity is the best.

Single-doped silica fume replaces part of the cement, and the same curing time in the tested dosage range increases with the increase in the dosage, and the strength increases in the early stage and the later stage is relatively slow. When the content of silica fume reaches $10 \%$, the performance of concrete reaches the best.

Double-doped silica fume and fly ash replace part of the cement. The strength of concrete increases first and then decreases. With the increase of mineral admixtures, the amount of cement decreases, resulting in relatively few high-strength cemented products, resulting in higher strength of concrete. low. When the content of fly ash is $10 \%$ and the content of silica fume is $10 \%$, the compressive strength of concrete reaches the best at each age.

\section{References}

1. Tian Shuai, Lu Jianfeng, Li Shihua, Wang Junjie \& Wang Mobi. (2020). The influence of mineral admixtures on the durability of high-performance concrete. Concrete and cement products (10), 12-16.

2. Li Qingfu, Sun Zhenhua \& Zhang Haiyang. (2011). Experimental study on the influence of fly ash and silica fume on the strength of concrete. Concrete (05), 77-79.

3. Wang Junwei, Li Qiuyi, Qi Xiushan \& Yue Gongbing.
(2015). Research on the influence factors of highperformance concrete. Concrete (02), 94-97.

4. Li Shiyang. (2018). Research on the influence of mineral admixtures on concrete strength and permeability (Master's thesis, Harbin Engineering University).

5. Gu Zifeng, Lu Guanzhong, Huang Pai, Zhang Hao \& Yu Guanglong. (2018). Experimental study on the influence of fly ash and silica fume on the strength of concrete. Shanxi Construction (23), 104-106.

6. Zhang Haiyang, Guo Jun, Zhang Xuhui \& Li Weidong. (2014). The influence of fly ash and silica fume on the compressive strength of highperformance concrete. China and Foreign Highway (03), 312-316.

7. Ma Shaojun \& Zhang Huili. (2010). Preparation technology of double-doped silica fume fly ash highperformance concrete. (eds.) The second national hydraulic discharge building safety and anti-scouring new material development new technology application collection (pp.107-110).

8. Gao Wei \& Tai Surong. (2011). On the influence of silica fume on high-performance concrete. Brand and standardization (16), 49. 